Journal of Thermal Engineering, Vol. 4, No. 5, pp. 2371-2380, July, 2018

Yildiz Technical University Press, Istanbul, Turkey

\title{
EXERGO-ECONOMIC ANALYSIS OF MICROCHANNELS IN SINGLE-PHASE FLOW
}

\author{
M. R. Özdemir ${ }^{1}{ }^{*}$, Ö. R. Sözbir ${ }^{1}$, M. Yılmaz ${ }^{1}$
}

\begin{abstract}
With the increase of energy demand, many researchers tried to develop scientific approaches in order to design more efficient and environmentally friendly energy systems. Exergo-economic (thermoeconomic) analysis of a system or device is an efficient tool for evaluating the system in terms of the thermodynamic and economic aspects. In this parametric study, exergo-economic analysis of rectangular copper plain microchannels under single-phase flow conditions were investigated using de-ionised water. The exergo-economic performance was evaluated based on the relative cost difference and unit cost per product exergy tools. The channel aspect ratio effect on the unit cost per product exergy and relative cost difference was examined using three microchannel test sections with the same channel hydraulic diameter $\left(D_{h}=0.56 \mathrm{~mm}\right)$ and length $(L=62 \mathrm{~mm})$ but different aspect ratios $(\beta=0.5,2.56$ and 4.94$)$ under single-phase flow conditions. The results showed that the exergo-economic performances of the three microchannel test sections decreased as the net heat input increased over the experimental range. Moreover, the exergo-economic performance of test section $2(\beta=4.94)$ was found to be greater than the exergo-economic performances of test sections 1 and $3(\beta=0.5$ and 2.56$)$ at fixed flow rate and fixed net heat input case.
\end{abstract}

\section{Keywords: Exergo-Economic Performance, Microchannels, Thermo-Economics, Single-Phase Flow}

\section{INTRODUCTION}

Recent advances in the industry brought the appearance of miniature technological devices in the market. The heat dissipation rate from these compact and powerful devices is now becoming enormous [1-3]. The classical air cooling method cannot supply these high cooling load. For example, in a recent study that compared the efficiency of liquid-cooling and air-cooling systems reported $56 \%$ better thermal performance in the liquid-cooling method [4]. At this juncture, liquid-cooled microchannel heat sinks have become to take place in various applications such as mechanical, aerospace and other engineering applications over the past decade [5-8]. These extremely compact heat exchangers provide higher plant efficiency with reduced pumping power and waste production. On the other hand, the analysis based on the second law of thermodynamics (exergy analysis) measures the useful work potential of the system [9]. Exergy analysis helps to obtain efficiencies and energy losses of different components in complex thermodynamic cycles. In the literature, exergy analysis was found to be a powerful tool to evaluate the energy quality, therefore helps to increase the efficiencies of thermodynamic systems [10-12]. However, exergy analysis is not solely sufficient to design cost-effective systems in a world having finite natural sources. In those applications, it is required to combine the exergy analysis with economic analysis. The exergo-economic (thermoeconomic) analysis is one of the most widely used methods that evaluates the inefficiencies, the associated cost of these inefficiencies and the required investment expenditures to reduce them. The exergo-economic analysis provides an optimization for the system efficiency and associated cost. In the literature, many researchers used the exergo-economic analysis for various systems [13-18].

Okure et al. [13] applied the exergo-economic analysis to a small-scale Combined Heat and Power (CHP) system which is being used in heat exchangers, gas turbines, and heat recovery systems. They reported that $56.8 \%$ of the useful fuel is lost in the CHP system due to the irreversibilities. Moreover, they stated that the heat exchanger has the most exergetic loss $(3.55 \$ / \mathrm{h})$, therefore it should be modified. In another study, Villa et al. [14] presented an exergoeconomic analysis of a micro-cogeneration system. The system produces electricity and hot water using a natural gas fuelled microturbine and recovered waste heat from the exhaust gases. Their results showed that the system becomes cost-effective after the $5^{\text {th }}$ year based on the exergo-economic analysis. Fellah et al. [15] performed exergo-economic analysis for the gas turbine power plant located in Libya. The analysis showed that the cost of exergy destruction of the combustion chamber is the main responsible element in the total cost of exergy loss of the overall system.

This paper was recommended for publication in revised form by Regional Editor Tolga Taner 
Gorji-Bandpy \& Goodarzian [16] optimised operating parameters of a gas turbine power plant that produce $140 \mathrm{MW}$ of electricity using exergo-economic principles and genetic algorithms. Their analysis showed that the cost of the final product is $9.78 \%$ lower with respect to the base case. This was achieved with $8.77 \%$ increase in total capital investment. Koşar [17] conducted a parametric study of thermoeconomic performance over four micro pin fin heat sinks of different spacing and shapes. In order to evaluate the thermoeconomic performance, he utilised the unit cost per product exergy, relative cost difference, and exergo-economic factor. The authour has used two performance criteria, fixed mass flow rate and fixed pressure drop. He also investigated the effect of working fluid on the thermoeconomic performance using R-123 and water as working fluids. He concluded that the unit cost of exergy change decreases as the electrical power is increased, the relative cost difference approaches to unity at high electrical powers. High exergo-economic values are obtained at low electrical powers, whereas these values are small at high electrical powers. He also showed that using R-123 at both fixed mass flow rate and pressure drop, lower cost per Watts of the products can be obtained when compared with water. The author also mentioned that the effect of the geometric shape of microchannels on the unit cost per product exergy is insignificant at fixed mass flow rate. On the other hand, scarcely packaged pin fin heat sinks had higher unit costs at fixed pressure drop and unit cost per product exergy was independent of pin fin shape at fixed mass flow rate.

As seen from the above-mentioned studies, there are not enough studies in analysing the exergo-economic performance in plain micro-scale heat exchangers. There is one study [17] which analysed the exergo-economic performance in microchannels but the interest was pin fin devices. Therefore, our main aim in this study is to provide knowledge on exergo-economic performance in plain rectangular microchannels. Moreover, the effect of channel aspect ratio on the exergo-economic performance is presented in this study.

\section{DATA REDUCTION}

The experimental data utilised in this study are obtained from Özdemir's [18] experimental test setup. The data are procured from the voltage, current, mass flow rate, pressure measurements and thermocouple readings. The data were demeaned to the average wall temperatures, flow exergy rate and exergy destruction rate while the electrical input power and resistance were calculated using the measured voltage and current values. The average thermocouple temperature was obtained directly from the calibrated thermocouple reading. The closed loop experimental facility is made of stainless steel tubing and fittings which are designed to deliver the de-ionised water to the microchannel test sections at desired inlet conditions. For single-phase flow conditions, the system consists of several components as follows:
* Desktop computer
* Liquid tank
* Micro-gear pump
* Ultrasonic flowmeter
* Data acquisition system
* Purging system
* Microchannel test section

Temperature and pressure readings are obtained from the test rig via National Instrument data acquisition hardware system. A computer program was developed using the Labview V8 software program to process temperature and pressure signals collected during experiments. A photograph of the experimental facility is shown in Figure 1.

The microchannel test sections were heated using one $600 \mathrm{~W}$ cartridge heater inserted below the channel in a direction parallel to the flow that is located in a drilled $7 \mathrm{~mm}$ hole through the copper block. The local axial wall temperatures were measured in the $0.6 \mathrm{~mm}$ inner diameter and $6 \mathrm{~mm}$ length holes at the side of each microchannel test section. The holes were located $1.1 \mathrm{~mm}$ distance below the channel bottom to accommodate K-type thermocouples [18]. Relevant properties and their equations are given as follows. 


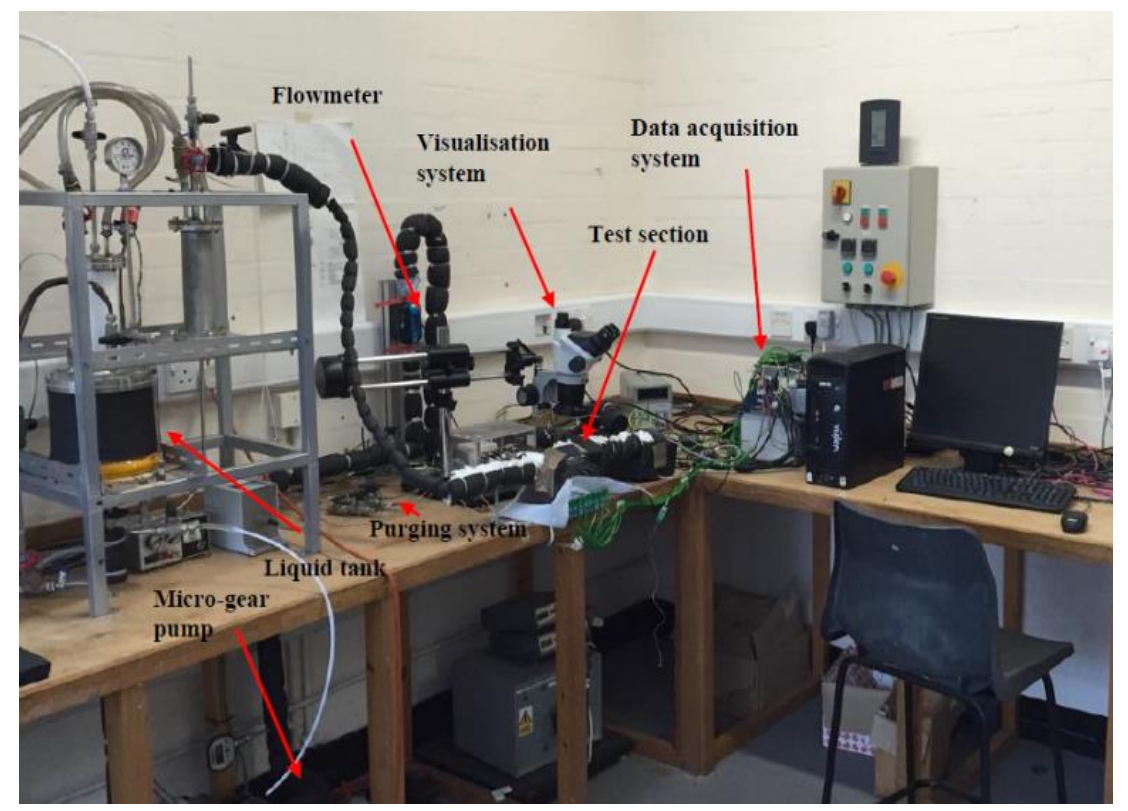

Figure 1. Photograph of the experimental facility. [18]

For simplicity net heat balance can be given as one term:

$$
\dot{Q}=P-\dot{Q}_{\text {loss }}
$$

where $P$ is the power of the electrical resistance heater and $\dot{Q}_{\text {loss }}$ is the heat lost from the test section. The heat balance could also be expressed as:

$$
\dot{Q}=\dot{m} c\left(T_{f, 2}-T_{f, 1}\right)
$$

where $T_{f, 1}$ and $T_{f, 2}$ are the temperatures of the de-ionised water at the inlet and exit, respectively and $\dot{m}$ is the mass flow rate in the microchannel. Under 1-D steady state heat conduction assumption, the average wall temperature at the base of the copper microchannel is expressed as:

$$
T_{w}=T_{t c}-\frac{\dot{Q} t}{k_{c u} A p l}
$$

where $T_{t c}$ is the average thermocouple temperature reading, $t$ is the distance from the channel bottom to the thermocouple location, which is $1.1 \mathrm{~mm}, k_{c u}$ is the thermal conductivity of copper and $A_{p}$ is the planform area of the housing of the microchannel test sections. The flow exergy is expressed as a function of specific enthalpy, entropy, kinetic and potential energy transfer, and environmental conditions:

$$
e x_{f}=h-h_{o}-T_{o}\left(s-s_{o}\right)+\frac{v^{2}}{2}+g z
$$

here $e x_{f}$ is the specific exergy of the flow, $h$ is the specific enthalpy, $s$ is the specific entropy, $v$ is the velocity of the fluid, $g$ is the gravitational acceleration, $z$ is the elevation and the subscript "o" represents the respective properties of the environment. A microchannel heat sink can be modelled as a one stream heat exchanger with continuous heat input as illustrated in Figure 2. 


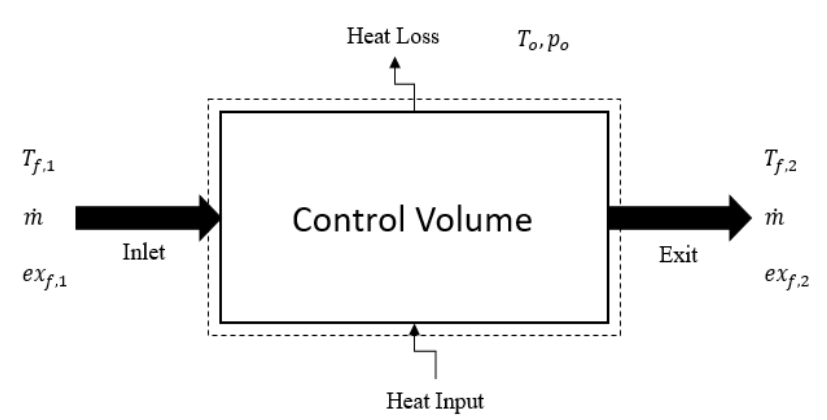

Figure 2. Schematic representation of the interaction between the micro heat sink and the environment.

where $e x_{f, 1}$ and $e x_{f, 2}$ are the specific exergies of the flow at the inlet and exit, respectively. $p_{o}$ is the ambient pressure. Based on the control volume illustrated in Figure 2, the following exergy balance could be stated under the steady state assumption [17]:

$$
0=\left(1-\frac{T_{0}}{T_{w}}\right) \dot{Q}-\dot{W}_{c v}+\dot{m} e x_{f 1}-\dot{m} e x_{f 2}-\dot{I}_{c v}
$$

where $T_{o}$ and $T_{w}$ are ambient and average wall temperatures, respectively. $\dot{W}_{c v}$ is the work done by the control volume, $\dot{I}_{c v}$ is the rate of change in irreversibility. Putting $e x_{f, 1}$ and $e x_{f, 2}$ into eq. (4) separately and then subtracting from each other and denoting as $(\alpha)$ gives:

$$
\alpha=e x_{f, 2}-e x_{f, 1}=h_{2}-h_{1}-T_{0}\left(s_{2}-s_{1}\right)
$$

The total exergy change between exit and inlet streams is the total products, $c_{\mathrm{p}}$ of the micro-scale heat sink. The exergy due to the heat input from the heater is considered as the input. The unit cost per Joules of the products can be expressed as a function of the exergies of product and the unit costs of investment and input electricity [17]:

$$
c_{p}=\frac{\left(1-\frac{T_{o}}{T_{w}}\right) \dot{Q} c_{e}+\dot{c}_{i n v}}{\dot{m} \alpha}
$$

where $c_{e}$ is the unit cost of input electricity and $\dot{c}_{i n v}$ is the unit cost rate of investment. The relative cost difference $(r)$ which is the ratio between the relative cost per product exergy to the electricity cost per rate of change of exergy due to the interactions and is expressed as:

$$
r=\frac{c_{p}-c_{e}}{c_{e}}
$$

In this study, exergo-economic analysis of metallic rectangular microchannel heat sinks was investigated with varying aspect ratios $(\beta)$ but fixed channel hydraulic diameter $\left(D_{h}=0.56 \mathrm{~mm}\right)$ and channel length $(\mathrm{L}=62 \mathrm{~mm})$ used under single-phase flow conditions, see Figure 3. Also a photograph showing the top view of a microchannel test section is given in Figure 4. The results are presented in the form of constant electrical power and flow rate and constant flow rate (increasing electrical power) conditions. The inlet temperature and inlet pressure were kept constant during the tests. The microchannel test sections have single rectangular channel and circular inlet/outlet plenums. The geometrical parameters of the microchannels are presented in Table 1. 


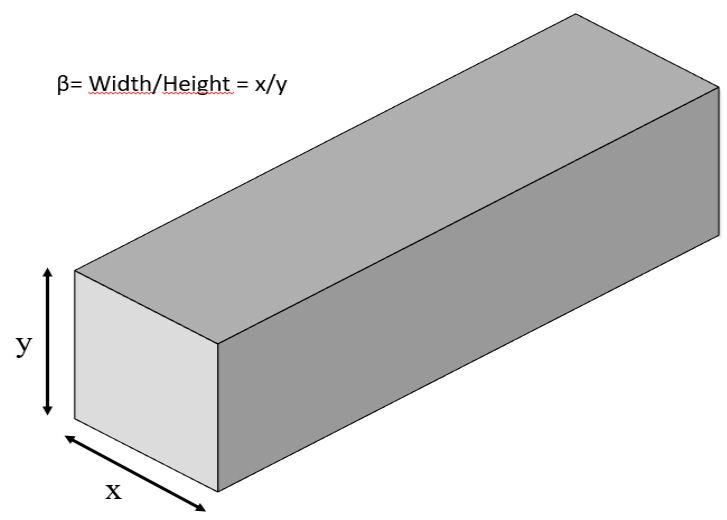

Figure 3. Schematic representation of the aspect ratio of the microchannel heat sinks in this study $(\beta=0.5-4.94)$.

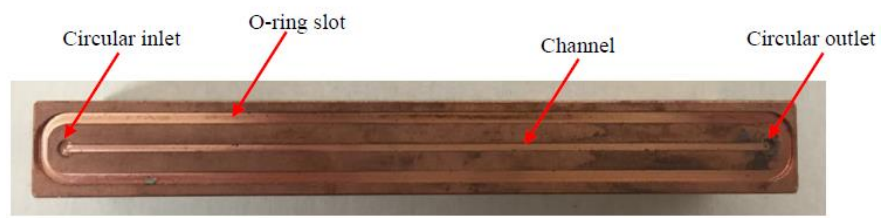

Figure 4. Photograph of a test section [18].

Table 1. Dimensions of the test sections

\begin{tabular}{|l|c|c|c|}
\hline $\begin{array}{l}\text { Test } \\
\text { Section }\end{array}$ & $\begin{array}{l}\text { Length, } \\
(\mathrm{mm})\end{array}$ & $\begin{array}{l}\text { Hydraulic } \\
\text { Diameter, } \\
(\mathrm{mm})\end{array}$ & $\begin{array}{l}\text { Aspect } \\
\text { Ratio }\end{array}$ \\
\hline TS1 & 62.0 & 0.56 & 2.56 \\
\hline TS2 & 62.0 & 0.56 & 4.94 \\
\hline TS3 & 62.0 & 0.56 & 0.5 \\
\hline
\end{tabular}

\section{RESULTS AND DISCUSSION}

In this section, the results of exergo-economic analysis of three plain microchannels are presented and discussed. The data in Table 2 are used as investment cost rates, $\dot{c}_{i n v}$. The fabrication procedure is standard; hence the fabrication price is same for all devices. In the calculation of $\dot{c}_{i n v}$, annual operating hours were assumed as 2080 hours ( 8 hours/day \& 5 days/week) and also the microchannels were assumed to be in service for 14 years. The electricity cost, $c_{e}$ is approximately $0.073 \$ / \mathrm{kWh}[19]$.

Table 2. Investment cost rates

\begin{tabular}{|lcc|}
\hline Budget item & Budget (in \$) & $\begin{array}{l}\text { Budget per device } \\
\text { ( in \$) }\end{array}$ \\
\hline Fabrication & 2265 (3 devices) & 755 \\
Pump + head & 960 & 960 \\
Fittings \& Tubing & 310 & 310 \\
Packaging & 580 & 580 \\
Flowmeter & 395 & 395 \\
\hline Total cost: & 4510 & 3000 \\
\hline Investment cost per hour $(\$ / \mathrm{h})$ & 0.103 \\
Investment cost per second $(\$ / \mathrm{s}) \dot{c}_{i n v}$ & $2.86 \mathrm{E}-05$ \\
\hline
\end{tabular}

Figure 5 presents the unit cost per product exergy change $\left(c_{\mathrm{p}}\right)$ at constant flow rate and constant electrical power condition. Figure 5 shows that the unit cost per product exergy change of test section 2 (wider channel) is slightly 
higher $(0.00002 \$ / J)$ than the other test sections (TS1 and TS3) unit cost per product exergy change. These results imply that it is better to use TS1 and TS3 at constant flow rate and electrical power operating conditions in order to have reduced operation costs.

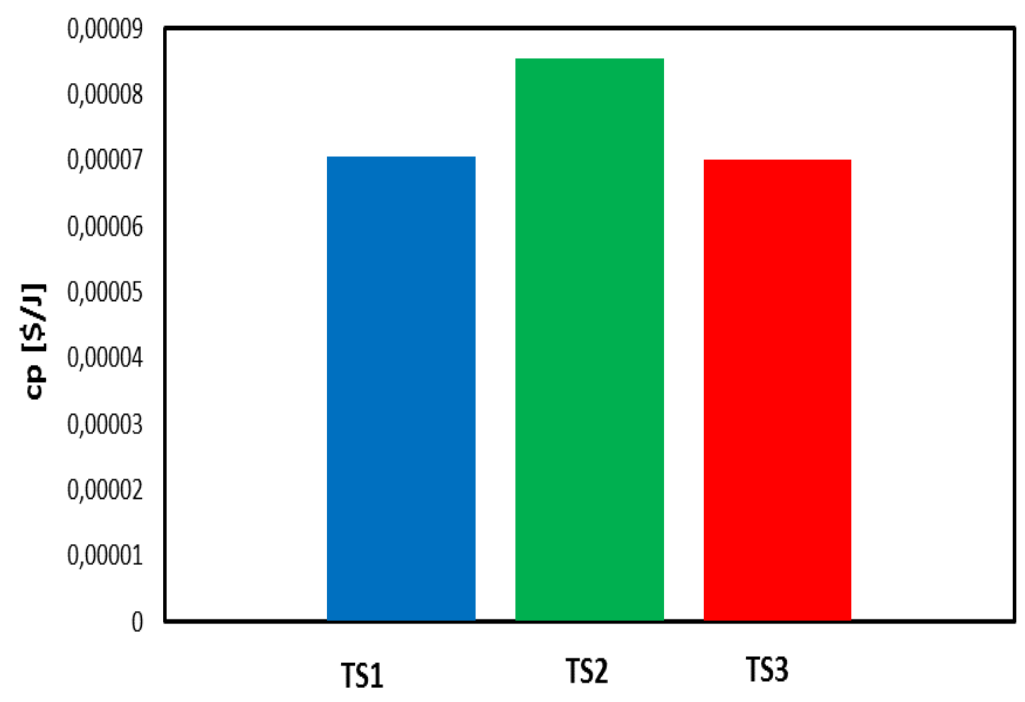

Figure 5. $c_{p}$ values of microchannel test sections at constant flow rate and constant electrical power.

Figure 6 displays the relative cost difference (r) at constant flow rate and constant electrical power condition. Since $r$ is strongly dependent on $c_{p}$ (see equation 8), similar behaviour of $r$ for test sections is expected. It can be inferred from figure 4 that the $c_{p}$ values of the TS1 and TS3 are closer to the electricity cost $\left(c_{e}\right)$ which confirms the results of figure 5 .

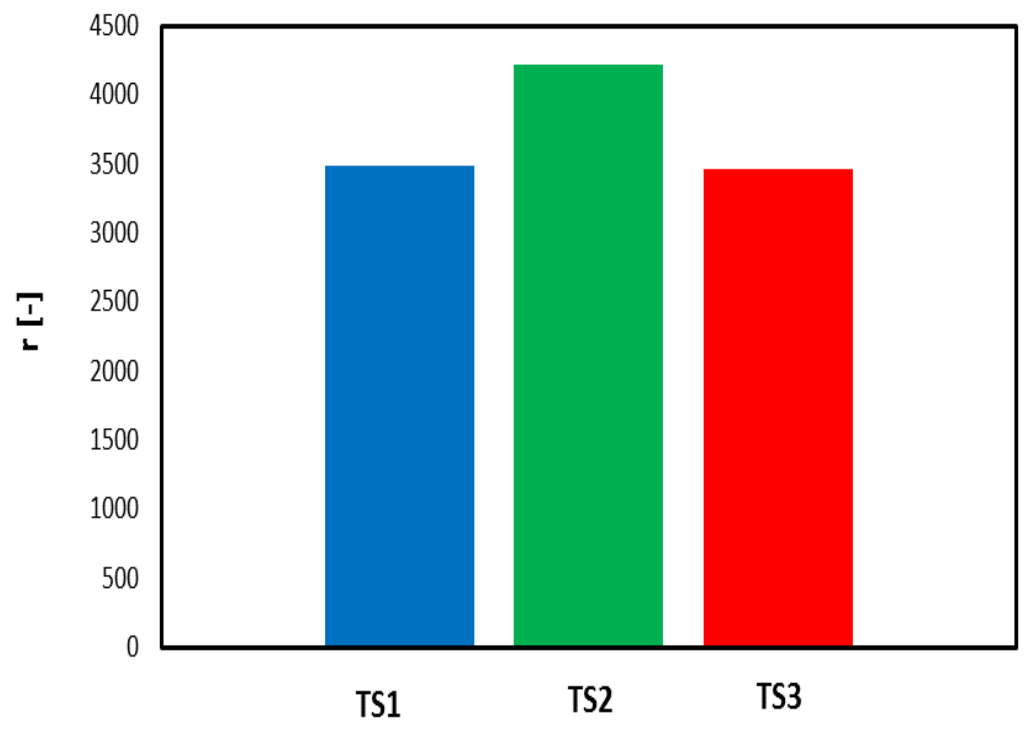

Figure 6. $r$ values of microchannel test sections at constant flow rate and constant electrical power.

The unit cost per product exergy change as a function of electrical power at constant mass flux operations ( $G$ $=800 \mathrm{~kg} / \mathrm{m}^{2} \mathrm{~s}$ and $\mathrm{G}=600 \mathrm{~kg} / \mathrm{m}^{2} \mathrm{~s}$ ) are depicted in figures 7 (a-b) for all microchannel test sections. As can be seen from figures $7(\mathrm{a}-\mathrm{b})$, the unit cost per product exergy change decreases with the increase in electrical power at constant flow rate conditions. Therefore, microchannel heat sinks should be operated at high electrical powers to obtain lower operation costs. These findings match those observed in earlier studies [17]. In that study, the authour reported that the micro pin fin heat exchangers are cost and performance effective at higher electrical power operations (more than 10 
W). Moreover, figures 7 (a-b) shows that the channel aspect ratio effect on the unit cost of exergy change is insignificant at constant flow rate and increasing electrical power conditions.

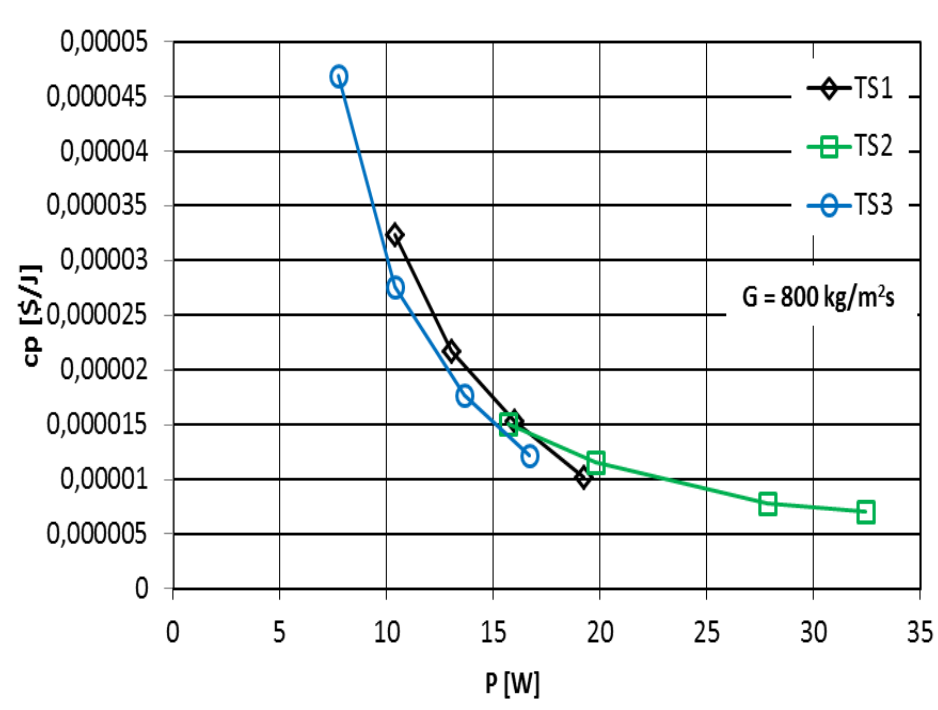

(a)

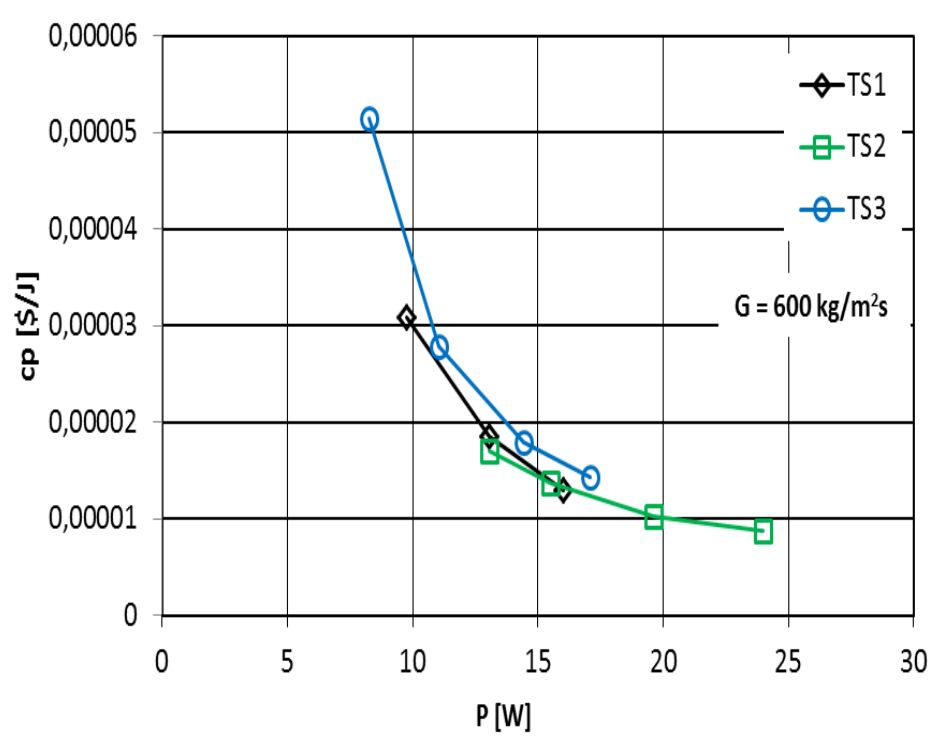

(b)

Figure 7. $c_{p}$ values of microchannel test sections as a function of electrical power: (a) at $G=800 \mathrm{~kg} / \mathrm{m}^{2} \mathrm{~s}$, (b) at $\mathrm{G}=$ $600 \mathrm{~kg} / \mathrm{m}^{2} \mathrm{~s}$.

Accordingly, the relative cost differences ( $r$ ) of three microchannel heat sinks as a function of electrical power are plotted in figures $8(a-b)$. As stated above, $r$ shows the same pattern with $c_{p}$. Therefore, figures $8(a-b)$ further support the idea of operating microchannel heat sinks at high electrical powers. It can be inferred from figures 8 (a-b) that the unit cost per product exergy change approaches to electricity cost as the electrical power is increased. 


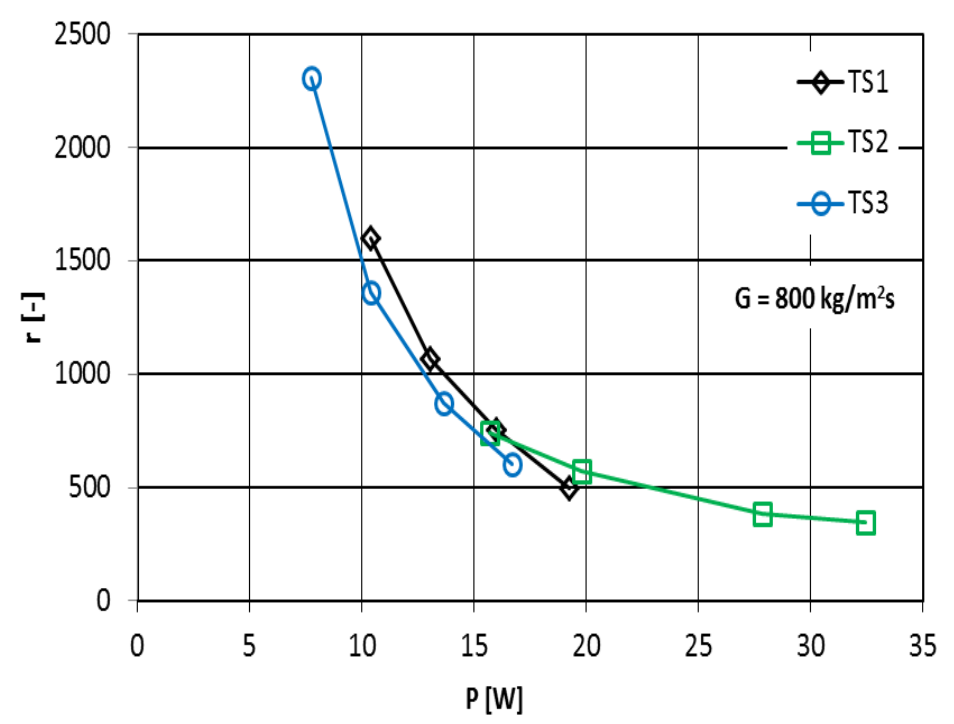

(a)

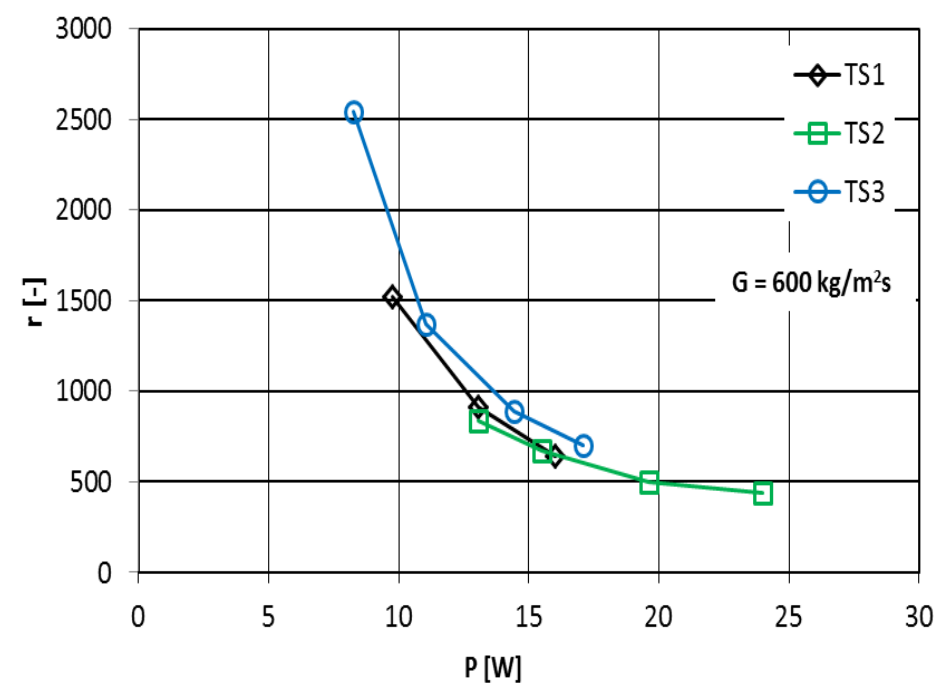

(b)

Figure 8. $r$ values of microchannel test sections as a function of electrical power: (a) at $G=800 \mathrm{~kg} / \mathrm{m}^{2} \mathrm{~s}$, (b) at $\mathrm{G}=$ $600 \mathrm{~kg} / \mathrm{m}^{2} \mathrm{~s}$.

\section{CONCLUDING REMARKS}

Exergo-economic analysis of three plain rectangular microchannels was conducted under single-phase conditions for constant electrical power and constant flow rate, and constant flow rate with increasing electrical power conditions. The unit cost per product exergy change $\left(c_{p}\right)$ and relative cost difference $(r)$ values were evaluated. The results showed that the unit cost per product exergy change values of TS1 $(\beta=2.56)$ and TS3 $(\beta=0.5)$ are slightly lower in comparison to TS2 $(\beta=4.94)$ at constant flow rate and constant electrical power operations. These findings suggest that using microchannels having smaller aspect ratios is more cost-effective than using microchannels with large aspect ratios at constant electrical power and constant flow rate operations. Furthermore, the unit cost per product exergy change and relative cost difference values decreased as the electrical power increased at constant flow rate conditions. Therefore, microchannel heat sinks should be employed at high electrical powers in order to have lower operational costs. Also, it was found that the channel aspect ratio effect on the unit cost per product exergy change and the relative cost difference is not notable at constant flow rate and increasing electrical power conditions. 


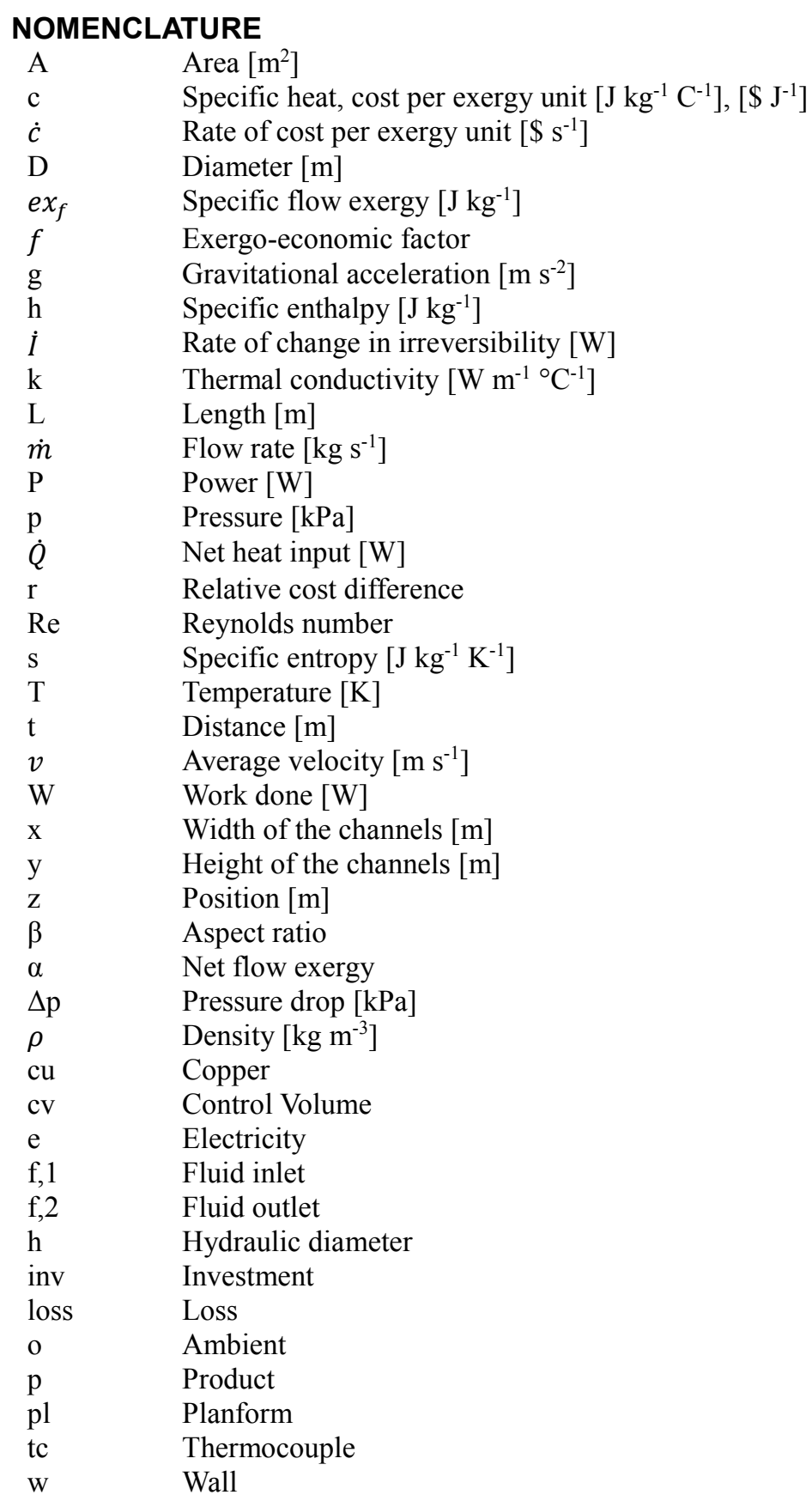

\section{ACKNOWLEDGEMENT}

The first author acknowledges to the Brunel University London for the experimental facility.

\section{REFERENCES}

[1] Lee, J., Mudawar, I. (2009). Low-temperature two-phase microchannel cooling for high-heat-flux thermal management of defense electronics. IEEE transactions on components and packaging technologies, 32(2), 453-465.

[2] Ali, R. (2010). Phase Change Phenomena During Fluid Flow in Microchannels (Doctoral dissertation, KTH).

[3] Kadam, S. T., \& Kumar, R. (2014). Twenty first century cooling solution: Microchannel heat sinks. International Journal of Thermal Sciences, 85, 73-92.

[4] Xu, S., Guo, Z., Hu, G., Chen, W., Lewis, R., Wong, C. N. (2014). Thermal and flow fields in single board computer cabin systems using CFD analysis. Engineering Applications of Computational Fluid Mechanics, 8(4), 574-585.

[5] Dix, J., Jokar, A., Martinsen, R. (2008). A microchannel heat exchanger for electronics cooling applications. In ASME 2008 6th International Conference on Nanochannels, Microchannels, and Minichannels (pp. 1935-1936). American Society of Mechanical Engineers. 
[6] Bulut, M., Sozbir, N. (2015). Analytical investigation of a nanosatellite panel surface temperatures for different altitudes and panel combinations. Applied Thermal Engineering, 75, 1076-1083.

[7] Tabeling, P. (2007). Introduction to microfluidics. New York: Oxford University Press.

[8] Tuckerman, D. B., \& Pease, R. F. W. (1981). High-performance heat sinking for VLSI. IEEE Electron device letters, 2(5), 126-129.

[9] Kumar, R. (2016). A critical review on energy, exergy, exergoeconomic and economic (4-E) analysis of thermal power plants. Engineering Science and Technology, an International Journal.

[10] Pavelka, M., Klika, V., Vágner, P., Maršík, F. (2015). Generalization of exergy analysis. Applied Energy, 137, 158-172.

[11] Şöhret, Y. (2018). Exergo-sustainability analysis and ecological function of a simple gas turbine aero-engine. Journal of Thermal Engineering (JTEN), 4(4), 2083-2095.

[12] Koroglu, T., Sogut, O.S. (2017). Advanced exergy analysis of an organic rankine cycle waste heat recovery system of a marine power plant. Journal of Thermal Engineering (JTEN), 3(2), 1136-1148.

[13] Okure, M. A., Musinguzi, W. B., Sebbit, A., Løvås, T. (2014). Exergoeconomic analysis of a novel small $\square$ scale CHP system for rural electrification in Uganda. International Conference on Heat Transfer, Fluid Mechanics and Thermodynamics.

[14] Villa, A. A. O., Dutra, J. C. C., Guerrero, J. R. H., dos Santos, C. A. C. (2016). Techno-economic and exergoeconomic analysis of a micro cogeneration system for a residential use. Acta Scientiarum. Technology, 1(1), 327-338.

[15] Fellah, G. M., Mgherbi, F. A., Aboghres, S. M. (2010). Exergoeconomic analysis for unit Gt14 of South Tripoli gas turbine power plant. Jordan Journal of Mechanical and Industrial Engineering, 4(4), 507-516.

[16] Gorji-Bandpy, M., Goodarzian, H. (2011). Exergoeconomic optimization of gas turbine power plants operating parameters using genetic algorithms: a case study. Thermal Science, 15(1), 43-54.

[17] Koşar, A. (2011). Exergo $\square$ economic analysis of micro pin fin heat sinks. International Journal of Energy Research, 35(11), 1004-1013.

[18] Özdemir, M. R. (2016). Single-phase flow and flow boiling of water in rectangular metallic microchannels (Doctoral dissertation, Brunel University London).

[19] Invest in Turkey, Investment Support and Promotion Agency of Republic of Turkey. http://www.invest.gov.tr/enUS/investmentguide/investorsguide/Pages/BusinessPremises.as 